\title{
POSIBLE IMPACTO PARÓDICO DEL TITULO: LA VIDA DE LAZARILLO DE TORMES, Y DE SUS FORTUNAS Y ADVERSIDADES
}

\author{
Clark Colahan y Alfred Rodriguez. \\ Whitman College y The University of New Mexico.
}

Según el agudo y conjetural estudio del profesor Rico, el título tradicional de esta joya literaria — que no llevaría, en la estimación de este erudito, el manuscrito-carta que sirviera de base para la edición princeps, hipotéticamente burgalesa ${ }^{1}$ - sería obra de un muy poco inteligente pero muy perezoso cajista en la imprenta de Juan de Junta ${ }^{2}$. Así, circulando en forma de carta-manuscrita, sin título, el original proto-princeps hubiera parecido, se nos sugiere, mucho más como una carta que efectivamente escribiera, así, un mucho más verosímil pregonero/corresponsal ${ }^{3}$. Para comprobar la inautenticidad del título el profesor Rico insiste en lo anacrónico del diminutivo, por no utilizarse, como norma general, en la novela ; pero el hecho es que el propio erudito ha de anotar, diluyendo su argumento, que el diminutivo ocurre por lo menos una vez en ella ${ }^{4}$. Además, semejante argumento, aun cuando se hubiese podido presentar en términos absolutos, dista mucho de ser, por sí mismo, poderosamente convincente. Un título, con función propia, no tiene por qué mantenerse sin desviación siquiera mínima de los usos y normas del texto. Posteriormente, por reforzar su tesis de un título ajeno al autor del texto del Lazarillo, hace notar lo latinizante que es la segunda parte del mismo, 'y de sus fortunas y adversidades', indicando que semejantes construcciones tienen su paralelo en los epígrafes, que tampoco considera de mano del autor ${ }^{5}$. Pue-

1 Véase F. Rico, Problemas del Lazarillo, Madrid, Cátedra, 1988, pág. 151.

2 Ibid., págs. 137-46.

3 Ibid., pág. 151.

4 Ibid., pág. 139.

- Véase Lazarillo de Tormes, edición de F. Rico, Madrid, Cátedra, 1987, prólogo, pág. 2. 
de muy bien indicarse, otra vez, que la variada función del título (de los epigrafes también) puede promocionar diferencias, hasta esenciales, cara al lenguaje o el proceder lingüistico del texto. En general, debe subrayarse que no cabe descartar y enajenar lo diferente en tales elementos sin antes agotar, rechazándolas metódicamente, las posibles intenciones literarias que pudieran reflejar las diferencias señaladas.

Ahora bien, existe una conservadora resistencia humana a que desaparezca de un plumazo el título de una obra clave de toda una época de nuestra cultura, que no merezca ya el interés de una erudición que busque iluminar o explicar el texto que le sigue o el móvil creativo de su anónimo autor. Esta natural resistencia se ceba y crece ante la imprescindible presencia, exigida por la tesis del indicado estudioso, de un cajista pecaminosamente omnipotente, sin perro que le ladrara ni editor que le supervisara.

Pero ni con conservadoras corazonadas, ni con meramente señalar la ingeniosa creatividad (tan novelesca, casi, como la del anónimo autor) que supone la irrupción en la historia literaria de ese picaresco cajista, cabe recuperar el consagrado título. Para restituirlo, tras la perspicaz conjetura del profesor Rico, habría que darle un lógico e imprescindible papel dentro del conjunto literario del Lazarillo, función que en modo alguno podria resultar, verosímilmente, del complejo de azares que el profesor Rico reconstruye para su cajista tonto e indolente.

La erudición sobre el Lazarillo no ha hecho hincapié en la problemática que supondría, precisamente por lo innovador del intento novelesco que es el Lazarillo, el título de la obra. El único análisis del título completo (tantas veces omitido en las ediciones modernas ${ }^{6}$ ) que conocemos, el de Francisco Ayala, indica, en buena lógica, la resolución más inmediata de esa problemática mediante el eco incorporado ('y de sus fortunas y adversidades') de las biografías auténticas que le precedieron:

Muy otra sería al respecto la situación del lector a mediados del siglo xvi. Por lo pronto, reconocería de inmediato en ese título la manera ampulosa y enfática, la retórica solemnidad y buscado decoro que por entonces se estila dar como encabezamiento a las biografías de grandes personajes. Ya MorelFatio había llamado la atención sobre un libro impreso en 1526 bajo el título de Les fortunes et adversitez du feu noble homme Jchan Regnier, escuyer, en son vivant seigneur de Garchy et bailly d'Aucerre; pero Cejador, recogiendo esa nota, pretende rebajar su interés con la alegación de que ambas obras no se asemejan para lo demás en nada, fuera de ese complemento, "fortunas y adversidades", en el título del Lazarillo. Precisamente es ahí donde reside el valor de la coincidencia: el nombre lastimoso y vulgar de Lázaro, y todavía

- Véase, para el caso, la lista de ediciones del Lazarillo incluida en J. L. Laurenti, Bibliografía de la literatura picaresca, New York, AMS Press, 1973, págs. 61-75. 
reducido a familiar diminutivo, con el irrisorio apelativo "de Tormes" aparece incluido en un contexto de empaque heroico, creando un contraste que presta al conjunto inflexión cómica?

Ayala, como se ve, postula la función cómico-paródica que adelanta el título sobre el innovador carácter anti-heroico del gran librito. Es decir, sobre el hecho fundamental de que el Lazarillo, en un contexto de literatura heroico-caballeresca, abre una dimensión insólita, anti-heroica, para la narrativa española en prosa. No está mal que la crítica contemporánea, agotando algo las agudezas, haya estrechado su interés sobre los aspectos narratológicos del texto, subrayando la estructura epistolar de la obra, llevando el centro de gravedad autobiográfico (contra el patente énfasis pueril, en términos cuantitativos, del propio texto) hacia el narrador/corresponsal maduro y dándole un extraordinario relieve al 'caso' que nunca queda, por cierto, del todo iluminado. Todo ello añade riqueza, $\sin$ duda, a la pequeña joya que es el Lazarillo; pero sólo y siempre que ello no oscurezca, deparándolo al limbo de lo meramente incidental e imprevisto por el anónimo autor, el máximo logro de la obra, el revolucionario impacto literario que la hace fuente de toda una manera literaria y digna de estudio universal y constante: su consciente y paródica organización anti-heroica.

Con concederle al anónimo autor un mínimo de conciencia artística, habría que conceder, asimismo, que se sabía muy bien el impacto paródico, anti-heroico, que innovadoramente arrastraba su creación literaria. Y en tal caso, minimamente conjetural, habría también que pensar que su título iba dedicado a anunciar y reforzar ese revolucionario efecto. De hecho, esta función, paródicamente preparadora, es la que informa, como intentaremos demostrar, siguiendo al profesor Ayala, el sentido del título que estudiamos.

Es de notar que las biografías, más o menos heroicas, que este estudioso pone a continuación de lo ya citado llevan el nombre del personaje al final: Victorial o crónica del conde don Pedro Niño; Relación de los fechos del condestable Miguel Lucas Iranzo; Andanzas y viajes de Pedro Tafur ${ }^{8}$. La variación que sobre semejante esquema hace el autor del Lazarillo es la de anteponer el nombre del 'personaje' al anuncio de sus hechos, con lo cual, de salida, altera gráficamente, con indicio de inversión paródica, el título. Más importante, quizás, es que tal alteración, anteponiendo el nombre, le da pie

7 F. Ayala, El Lazarillo: reexaminado, Madrid, Taurus, 1971, págs. 22-23.

- La 'autobiografía' no tiene presencia genérica, como tal, en la España del dieciséis. Véase R. D. Pope, La autobiografía española hasta Torres Villarroel, Frankfurt, Peter Lang, 1974. En cuanto a la 'autobiografía' informal de la época, véase F. Lázaro Carreter, Lazarillo de Tormes en la picaresca, Barcelona, Ediciones Ariel, 1972, páginas 28-46. 
al autor para anticiparle al lector - mediante el nombre concreto seleccionado y su presentación en diminutivo- la calidad, anti-heroica de su obra.

Por lo tanto, la alteración gráfica del orden titular establecido para la biografia heroica, el anticipo, asi, del nombre anti-heroico y el signo irónico que de ese modo adquiere el recuento de hazañas ('fortunas y adversidades' 9 ), postergado, configuran un título de extraordinaria eficacia en la transmisión del carácter paródicamente anti-heroico de la novela. La titulación, editorialmente abreviada (olvidando "y de sus fortunas y adversidades"), que empieza a darse en impresiones modernas, de los siglos xix y xx ${ }^{10}$, puede reflejar la pérdida, con el pasar del tiempo, del valor paródico de esa última parte del título.

Pero hay otro toque paródico igualmente magistral en el título. $\mathrm{El}$ análisis que precede no considera un elemento que, por ser el primer sustantivo del título, encierra una importancia especial. La palabra 'vida', a la que nos referimos, no suele asociarse con la autobiografía-biografía real a la que se ha aludido más arriba como probable modelo paródico. Antes de la publicación del Lazarillo, no hemos hallado ni autobiografias ni biografías (con la excepción categórica que se verá en seguida) que comiencen con esa palabra. Por otra parte, ese mismo término suele encabezar, titularmente, las biografías de santos. El estudio de Aigrain deja constancia de esta particularidad de la literatura hagiográfica desde el principio, casi, de la era cristiana " tradición española es no menos reveladora en este sentido: $V$ ida de San Domingo de Silos, Vida de San Millán de la Cogolla, Vida de Santa Oria, de Berceo; Vidas de San Isidoro y San Ildefonso, del Arcipreste de Talavera; y, sin ir más lejos, en los días inmediatamente anteriores a la edición de Burgos y en la misma casa, se imprime, por ejemplo, La vida del bienaventurado Sant Amaro, y de los peligros que passó hasta que llegó al Parayso terrenal, como hace constar el propio Rico para facilitar su tesis ${ }^{12}$.

Pues bien, si, como parece, el comenzar un título con la palabra 'vida' venía vinculándolo de modo tan exclusivo a la biografía religiosa, cabe preguntar por qué lo había de emplear, como quiere el profesor Rico, ese cajista suyo ${ }^{13}$. La indolencia y la ignorancia habrían de haber sido abismales en el tal sujeto para haberlo hecho y la dejadez en el mismo grado, por parte del

- Para la interpretación de 'fortunas' como referencia a la 'rueda de la fortuna', que no concedemos, véase H. König, “(Anonym) : La vida de Lasarillo de Tormes y de sus fortunas y adversidades". Der Spanische Roman vom Mittelalter bis zur Gegenwar, editado por V. Roloff y H. Wentzlaff-Eggebert, Dusseldorf, Schwann Bagel, 1986, págs. 35-37.

10 Véase Laurenti, $o p$. cit., págs. 61-75.

11 Véase R. Aigrain, L'Hagiographie, Mayenne, Bloud \& Gay, 1953, cap. VII.

12 Véase Rico, Problemas, pág. 145.

13 Ibid., págs. 144-46. 
impresor, para haberlo permitido. Por otra parte, si nos preguntamos por qué habria de utilizar esa palabra vinculante el propio autor del Lazarillo, la respuesta lógica, dado el texto de que se trata, es que pretendia, con ello, aludir paródicamente a una forma biográfica cuyo contenido se hallaba en el polo opuesto al de la vida que iba a narrar. El nombre que sigue en el titulo no puede menos que recordar, como han visto los estudiosos ${ }^{14}$, a San Lázaro, el pordiosero santo del Evangelio de San Lucas, 16, xix-xxv, con diminutivo anticipatorio de su desvio picaresco y con una designación de origen, 'de Tormes', que resulta cómicamente paródica del santoral, rebosante también de nombres de santo con designación de origen.

Hemos de hacer constar que el modelo paródico en el que acabamos de insistir para el título del Lazarillo en modo alguno excluye la simultánea presencia, como antecedente parodiado, del modelo caballeresco (Amadís de Gaula, Palmerín de Inglaterra, etc.) que es a menudo sugerido por la crítica para esa función ${ }^{15}$. La coincidencia de la nominación titular religiosa-literaria y heroico-literaria, en todo menos en el uso del vocablo 'vida', le vino muy bien al autor del Lazarillo, redoblando el impacto anunciador de su propio título paródico.

Ahora bien, en su titulo, indicador prescrito del contenido del texto que le sigue, el perspicaz proto-novelista encerró invocaciones paródicas, como se ha visto, de las tres formas literarias que iba a invertir: la biografía-autobiografía real y heroica, su exagerada manifestación imaginativa en la literatura caballeresca y las vidas de santos. Como indica Alberto Blecua, "Dos temas cruzan, interfiriéndose, todo el Lazarillo; el de la honra y el religioso" 16. El tratamiento distorsionante de esos temas que el texto ofrece queda manifiestamente sugerido ya en la compleja parodia que es el título. Demasiado bien encaja éste en el diseño anti-heroico del Lazarillo, nos parece, para que se pueda relegar, sin más, a la ineptitud de un perverso cajista.

14 Véanse B. Wardropper, "The Strange Case of Lázaro González Pérez", Modern Language Notes, 92, 1977, págs. 204-208; y A. D. Deyermond, Lazarillo de Tormes: A Critical Guide, London, Tamesis Books, Ltd., 1975, pág. 28.

15 Véase, por ejemplo, M. R. Lida de Malkiel, "Función del cuento popular en el Lazarillo de Tormes". Actas del Primer Congreso Internacional de hispanistas, Oxford, The Dolphin Book Co., Ltd., 1964, pág. 351.

${ }_{16} L a$ vida de Lazarillo de Tormes $y$ de sus fortunas $y$ adversidades, edición de A. Blecua, Madrid, Clásicos Castellanos, 1972, pág. 31. Para el estudio de cada uno de estos temas centrales, con sus múltiples manifestaciones, véase A. Francis, Picaresca, decadencia, historia, Madrid, Gredos, 1978, caps. III y IV. 